\title{
ALGUNS PROBLEMAS E ASPECTOS DO FOLCLORE TEUTO-BRASILEIRO *
}

\author{
Egon Schaden \\ Professor da Universidade de São Paulo
}

Desde que se fala em folclore, os autores têm divergido quanto à sua conceituação, à delimitação de seu campo e à formulação de seus problemas centrais. E não nos propomos discutir neste trabalho as divergências que persistem. Basta dizermos que a nosso ver as investigaçóes devem situar-se no âmbito mais amplo da Antropologia Cultural, a fim de serem crientadas por uma teoria geral da cultura, em vez de se procurar estakelecer uma "ciência do folclore" mais ou menos autônoma, com métodos de pesquisa e princípios de interpretação próprios. Preferimos conceber o folclore simplesmente como determinada ordem de fenomenos culturais relativos ao saber, à arte, às técnicas e aos costumes populares, isto é, tradicionais e de autoria em geral anônima, em oposição a criações análogas de origem erudita ou cientifica. Se para as sociedades primitivas não lem, de ordinário, sentido a distinção entre as duas categorias de fenômeros, ela pode ser útil no estudo das formas de vida rurais e urbanas, onde não raras vêzes se impõe de maneira por assim dizer natural.

Em nosso meio, o estudo do folclore tem estado quase sempre a cargo de "curiosos" sem preparo científico especializado, incapazes, por isso, de aplicarem um método de pesquisa bastante rigoroso e de situarem as suas observações, por vêzes valiosas, com relação a determinadas preocupações teóricas. Limitam-se, por conseguinte, à coleta de certo número de fatos brutos, mais ou menos desconexos. Nem por isso o valor de seu esforço deve ser subestimado. Não fôsse o seu entusiasmo e a sua dedicação, pouco ou quase nada se teria feito e muita coisa estaria irremediàvelmente perdida. Quer nos parecer, todavia, que também no Brasil é chegada a hora de a investigação do folclore superar a fase da coleta assistemática e ocasional, (lesprender-se das peias do diletantismo e elevar-se a um nivel verdadeiramente científico. Reconhece-se que não seria difícil apontar uma série de estudiosos mais ou menos isolados que, com alguns resultados já auspiciosos, se empenham nessa tarefa de renovação. Mas não é suficiente. Cumpre que as instituições de ensino superior e outras entidades qualificadas comecem a dar impulso e organização a êsse movimento, que, aliás, conta

*) Trabalho apresentado ao $10^{\circ}$ Congresso de Dialectologia e Etnografia, realizado em Pôrto Alegre, de $1 .^{\circ}$ a 8 de setembro de 1958. 
agora com apoio oficial através da Campanha de Defesa do Folclore, recentemente criada no Ministério de Educação e Cultura. Sem que nos inclinemos a compartilhar do pânico da undécima hora, comum entre antropólogos, e etnógrafos em particular, parece-nos que não há tempo que perder. de vez que as fôrças homogenizadoras da civilização vão destruindo rom crescente rapidez as criaçóes do chamado "espirito popular". Que se promova, pois, a coleta sistemática de objetos em museus especializados, hem como o levantamento, quer foto e cinematográfico, quer sonográfico dos elementos característicos nas nossas formas tradicionais de vida. E que se organize, à base dêsses dados, o mapa cultural do Brasil, ponto de partida indispensável para quaisquer empreendimentos de maior fôlego.

Os Estados meridionais, pela fisionomia peculiar que tomaram através da colonização estrangeira dêstes últimos cento e trinta anıs, ou seja, através da interação de etnias e culturas díspares, constituem area sobremodo rica em possibilidades para observações de interêsse teórico menos restrito. Melhor do que em outras partes do Brasil é aqui que se podem captar ao vivo não apenas tais ou quais fatos curiosos ou interessantes, mas a própria dinâmica dos processos responsáveis pela formação de um folclore novo, no qual se integram, ronstituindo um todo harmonioso, elementos tradicionais uns, e de variada procedência, recentes outros. O campo mais promissor dessa área nô-lo oferecem as populações teuto-brasileiras, não só por serem mais numerosas que as demais, como ainda por provirem de uma terra ela própria altamente diferenciada quanto às suas tradições regionais. O embate dêsses folclores regionais entre si, como o seu ajustamento às peculiaridades do novo ambiente natural e o seu encontro com tradições de outra proveniência étnica, vieram desencadear fôrças, ora de persistência, ora de criação, que talvez estivessem latentes nas respectivas variantes rurais da cultura alemã, mas que em situação diversa não teriam passado de meras possibilidades.

No entanto, convém que êsses fatos sejam estudados com referência às transformações que se têm dado e se vêm dando no sistema total da cultura teuta em ambiente brasileiro e, em particular, à aculturação lingüística. Na medida em que as mudanças ocorridas no folclore são reflexo de mudanças de mentalidade - e o são em larga escala, como sabemos -, clas encontram expressão concreta e, por assim dizer, palpável no idioma. E' por isso que os aspectos da aculturação lingüística nos núcleos coloniais teuto-brasileiros não devem passar desapercebidos a quem queira surpreender as relações entre, digamos, a "psicologia étnica" do brasileiro de ascendência germânica e as suas criações culturais próprias. Daí julgarmos caberem neste contexto algumas considerações fundamentais sôbre as transformações sofridas pelo linguajar dos colonos no meio natural e cultural do Brasil. 
Dir-se-ia talvez que depois dos trabalhos de Willems e de outros sòbre a aculturação lingüistica nas populações teuto-brasileiras, os aspectos principais dêsse processo deveriam estar suficientemente esclarecidos, pelo menos para qualquer pessoa versada em assuntos de Antropologia Cultural. Tal, porém, não se dá. A prova encontramo-la, por exemplo, nas palavras com que um especialista. Artur Ramos, procurou resumir os resultados daquelas pesquisas. "Um dos traços culturais onde essa vacilação cultural se manifesta de maneira tipica é a língua. No léxico, como na fonologia ou na sintaxe, verifica-se verdadeiro conflito lingüistico, onde o português entra em luta com o alemão, com o predomínio eventual de um sóbre outro, mas em outros casos, com a formação de um curioso sincretismo lingüístico. São inúmeras as expressões portuguêsas adaptadas ao idioma alemão. A germanização dos verbos portuguêses pelas desinências "ieren" e "en" são comuns, como por exemplo, multieren, multar; sellieren, selar; konversieren, conversar etc."1.

Para se entender o que seja a "vacilação cultural" a que aí se faz referência, é preciso lembrar que o autor, invocando os trabalhos de Willems, a encara como "ressentimento social" do imigrante, que êste revelaria "na ambivalência de atitudes, hesitando entre a cultura brasileira e a cultura germânica, em inúmeras manifestações externas, de traços culturais, ou internas, cle atitudes e sentimentos, que por sua vez se refletem nas opinióes e atos sociais" 2 .

Ora, não é neste plano que nos parece acertado colocar os aspectos da aculturação lingüística teuto-brasileira apontados por Artur Ramos no trecho citado. Conflitos culturais, inclusive no campo idiomático, não podem ser interpretados, sem mais nem menos, como resultantes de quaisquer ressentimentos sociais. E' certo que a marginalidade cultural não pode deixar de manifestar-se como insegurança e vacilação, mas não há nisso nenhum ressentimento. Quando êste existe, é antes conseqüência do conflito lingüístico, e não sua causa ou sequer sua manifestação típica.

Mais ainda. Não se pode, à luz das poucas investigações feitas, dizer que haja sempre uma "luta" entre os dois idiomas, que ora conduza ao domínio de um sôbre o outro, ora a formações sincréticas. Isto, porque não se trata necessàriamente de formas diversas de acomodação de um mesmo conflito cultural, mas, pelo menos nos casos típicos, de fases diferentes, o que quer dizer: de situações sucessivas. O sincretismo resulta de quase tôdas as situações de contacto e, na hipótese de continuar a ação dos fatôres que o produziram, ou de se lhe acrescentarem outros, a aculturação prossegue, podendo levar ou ao bilingüismo ou ao uso exclusivo do português. (Este último caso, em que se adota o uso exclusivo do vernáculo, sem a passagem pela situação intermediária duma geração bilingüe, dificilmente se há de verificar numa comunidade inteira, mas em certas situacões familiais, em que, por exemplo, o casamento do teuto com mulher 
Iuso-brasileira pode não proporcionar aos filhos as condições necessárias para o aprendizado da língua do pai). E' o que as pesquisas de que dispomos permitem afirmar. Como em tôdas as esferas da cultura, a aculturação lingüística deve ser analisada como processo, isto é, como realidade dinâmica, como sucessão de fases, cada qual decorrente das características da situação anterior, e tendendo para a subseqüente pela ação de uns tantos fatôres, que convém descobrir. E não se há de esquecer a existência duma constante substituição funcional de fatôres. O sincretismo do linguajar teuto-brasileiro se nos afigura ora preponderantemente como fenômeno de estabilização lingüística provisória (que se mantém enquanto permanece o isolamento, portanto sobretudo no meio rural), ora como estágio intermediário ou correlato ao bilingüismo (em regiões semi-urbanizadas ou em núcleos urbanos). Quanto à sucessão das fases, esta decorre da ação de fatôres aculturativos diferentes. Pode, por exemplo, numa primeira fase manifestar-se apenas o fator da utilidade (a adoção de uma denominação para uma realidade geográfica ou um elemento cultural novo) e em outra prevalecer o da distinção social (o emprêgo do português para definir o statụs de cidadão em face da população luso-brasileira).

Parece não haver especial interêsse científico em compilar indiscriminadamente extenso vocabulário de todos os têrmos de origem portuguêsa até hoje registrados no linguajar de populações teuto-brasileiras nas mais diferentes situaçôes ecológicas, em comunidades rurais e sociedades urbanas, que, ademais. se espalham por um território cuja extensão abrange vários estados. Cumpre distinguir entre o vocabulário rural e o urbano e atender, em particular, à situação de mono e bilingüísmo. Nas populações bilíngües há sempre um acervo de vocábulos estranhos que se infiltram de modo generalizado no idioma de origem, ao lado de outros que traduzem predileções ou experiências individuais ou, em muitos casos, um grau mais ou menos adiantado de aculturação lingüística. Nas populações unilingües a situação é diversa. Os têrmos estranhos são assimilados peIn idioma em sentido rigoroso da palavra, nela se integrando como se aí tivessem nascido, e os que falam a língua cêdo perdem a consciência de que se trata de elementos nela infiltrados.

Como quer que seja, para melhor se definirem tais ou quais setores em que, através das mudanças sofridas no ambiente brasileiro, o idioma reflete certas tendências de transformação ou de criação no domínio do folclore, reconhecemos de bom grado que não deixa de haver utilidade num inventário geral sistematizado das peculiaridades do linguajar teuto-brasileiro, quer no tocante ao vocabulário, quer ao emprêgo de metáforas ou imagens sigqificativas. Neste sentido, possuímos, aliás, valiosa contribuição da autoria de Carlos Henrique Oberacker Júnior ${ }^{3}$. Uma análise do rico material ali apresentado, e reunido, aliás, com paciência beneditina, revelaria, estamos certos, interessantes traços da "psicologia étnica" do ho- 
mem teuto-brasileiro em sua maneira peculiar de compreender e sentir as características da paisagem natural e humana com que está em interação. E todos nós sabemos que ai está uma das fontes mais vivas de tôda criação folclórica.

Mas não nos alonguemos nesta ordem de considerações, sob pena de nos afastarmos demais do assunto de nossa exposição. Basta insistirmos uma vez mais na conveniência ou necessidade de se formularem os problemas de aculturação lingüística o quanto possível em têrmos sócio-antropológicos para que a sua análise nos abra perspectivas aproveitáveis para uma melhor compreensão dos fatos folclóricos da área em aprêço.

Passemos, então, para a discussão de alguns aspectos ou fatos do fol. clore teuto-brasileiro. Limitamo-nos a certas crenças populares e práticas mágicas, reconhecendo de bom grado que, embora tenhamos êsses elementos por significativos, talvez não se incluam entre os mais importantes para uma caracterização da personalidade cultural da população de origem germânica tomada em conjunto. No campo do folclore teuto-brasileiro tudo ou quase tudo está por fazer. Tanto na cultura cabocla das diferentes regiões do Brasil como na cultura rural alemã não há talvez aspecto que, da parte dos estudiosos (especialistas ou não), tenha merecido atenção igual à despertada pelas manifestações folclóricas. Com referência ao homem teuto-brasileiro cumpre dizer exatamente o contrário: é o setor menos bem conhecido. Às vêzes chega-se mesmo a afirmar -. um tanto afoitamente, é verdade - a quase inexistência de tradições populares e de uma literatura oral no âmbito pròpriamente teuto-brasileiro. Apesar do evidente exagêro, não deixa de nisso haver um grão de verdade. Por mais que à primeira vista os elementos do folclore possam parecer "fossilizados" no seio duma configuração cultural, prendem-se, ora mais, ora menos, a determinadas características do mundo ambiente. E' por isso que o conhecimento aprofundado do folclore regional exige quase sempre noções precisas das particularidades geográficas, da fauna, da flora, de fenômenos meteorológicos especiais. E há folclores, por assim dizer, mais geográficos do que outros, mais ligados à topografia e a uns tantos caracteres do meio natural. As tradições populares alemãs, por €xemplo, o são muito mais do que as portuguêsas; é natural que isto se reflita na capacidade de sua sobrevivência num mundo geogràficamente diverso. Embora b€m familiarizado com a natureza brasileira das regióes que veio ocupar, o teuto-brasileiro ainda é muito novo na terra para ter criado um rico folclore próprio, que é sempre fruto de longa elaboração através de gerações sucessivas.

Mas - o que é importante - deve haver também. ao lado dum periodo bastante longo, certo grau de estabilidade cultural, isto é, a aculturação ou, em sentido mais amplo, a mudança cultural deve processar-se em ritmo relativamente lento. E' o que bem observou Raúl Deeke, quan- 
Ao, depois de verificar que "não existe um folclore regional em Blumenau e (que) os costumes e crenças dos blumenauenses são os dos brasileiros, em geral um pouco mesclados dos tradicionalismos de seus antepassados", acrescenta que "existia temporàriamente uma base sadia para a formação de um folclore regional, mas a rápida evolução fê-la desaparecer" 4. Segundo êsse autor, até aspectos lingüísticos que distinguem os colonos descendentes de alemães e que em certa medida poderiam interessar ao folclorista, desaparecem pela influência da instrução escolar 5 .

A constante dependência em que vive, nas atividades econômicas da lavoura, com relação às características do clima, conferem ao homem do campo um espírito atilado na observação e previsão de chuva, geada, granizo e outros fenômenos meteorológicos. Transferindo-se para ambiente novo, com condições climáticas inteiramente diversas, o colono alemão, trazendo consigo o acervo de experiência milenar nesse domínio, viu-se forçado a abandonar as regras tradicionais de previsão de tempo para substituí-las por conhecimentos mais adequados à realidade.

Louvando-nos em cuidadosa pesquisa há tempos realizada em São Bonifácio, colônia alemã do alto Capivari, no sul de Santa Catarina, que, aliás, durante várias geraçóes ficou pràticamente isenta de contactos com representantes de outras etnias, vejamos como o colono ali radicado teve e tem o espírito atento para a natureza, e em particular para o mundo animal, na elaboração de um "saber popular" original, que pouco ou quase nada tem a ver com as tradicionais "Wetterregeln" da terra dos antepassados. Para o teuto-brasileiro de São Bonifácio, há mamíferos, como o bugio e o ouriço-cacheiro, tidos como prognosticadores do tempo; tanto o ronco do bugio, que se ouve de dia, como os gritos do ouriço-cacheiro, ao anoitecer e às primeiras horas da noite, indicam que o período de sêca ainda não chegou ao fim. Muito maior é, porém, o número de aves que, pelo grito ou por certas formas de comportamento anunciam ou bom tempo ou chuva: a saracura (que, já no dizer de Fernão Cardim, "quando canta, de ordinário adivinha bom tempo"), as andorinhas, a jacupemba, os tucanos, o rabo-de-palha, o saci, o inhambu, o uru e outros mais. O grito do saci ou sem-fim, por exemplo, se interpreta, no dialeto da região, como "Git trüch" (haverá sêca) e o do rabo-de-palha como "Git Rejen" (vai (hover). Outras aves anunciam o inicio da primavera, ou melhor, o fim do período de geadas, marco decisivo no ciclo anual das atividades da lavoura ${ }^{6}$.

Estes e outros pormenores, por insignificantes que possam parecer, mostram em todo caso a facilidade com que o colono, pelos múltiplos laços que o prendem ao solo, cria uma cultura própria, atendendo ao imperativo de conhecer e explorar a natureza que o circunda. E mostram, uma vez ruais, que o folclore, em vez de se reduzir a elementos "fósseis" ou cristalizados, como não raro se afirma, está sujeito a constante processo 
dé criação. Em São Bonifácio nota-se, como vimos, a tendência de relacionar o mundo animal, especialmente a fauna regional, com a predição do tempo, atitude, aliás, comum na terra de origem. Mas o fato de se darem as explicações com referência a aves brasileiras já revela aculturação ou, pelo menos, inovação ou mudança cultural, a re-criação de elementos folclóricos novos em substituição a outros, destituídos de função no ambiente novo. Este "saber popular", que gira quase todo em tôrno de chuva e sêca ou bom tempo, mostra que o folclore não se transplanta de um meio §eográfico para outro sem nele ocorrerem mudanças incisivas.

Fato significativo para a compreensão da personalidade cultural do teuto-brasileiro é a ausência total - ou quase total - de qualquer forma de magia negra em seu folclore. Isto vale de um modo geral, tanto para as populações campesinas como para as da cidade. E' sabido que em algumas áreas rurais brasileiras essas práticas, por influência africana sobretudo, chegaram a ocupar lugar de relativa importância. A fraca disposição do teuto-brasileiro para aceitar traços dessa ordem é atitude seletiva decorrente da estrutura de sua personalidade. A êste respeito é de interêsse lembrar a explicação sugerida por Linton, segundo a qual a relutância na adoção de padrões de magia negra existentes em grupos vizinhos seria índice de sentimento de relativa segurança individual, revelando, por conseguinte, haver poucas hostilidades pessoais no seio da comunidade 7 . O leitor interessado em problemas antropológicos deve desconfiar do quadro sombrio de desnrganização social e desintegração cultural que depara, uma vez ou outra. em relatos de viajantes alemães que percorreram as colônias e que descrevem os colonos como dados a tôda sorte de brigas, com tiroteios e esfaqueamentos. O baixo índice de criminalidade da população teuto-brasileira já constituiria, por si só, razão ponderável para se porem de quarentena essas descrições.

Entre as fórmulas e práticas mágicas registradas em São Bonifácio não há uma sequer que se ligue à magia negra. As que se conhecem se referem em sua grande maioria ao tratamento dos males físicos, tanto em sêres humanos como nos animais. E parece que as benzeduras para curar moléstias humanas fazem parte, quase tôdas, do velho patrimônio cultural trazido da Europa, ao passo que os padrões para o tratamento dos animais foram aprendidos aqui. $E$ se um curandeiro da categoria de Diogo Pereira ${ }^{8}$ logrou conquistar o prestígio que veio a desfrutar na localidade, foi, antes de mais nada, como benzedor de animais. Não talvez porque os colonos se sentissem particularmente seduzidos pelos métodos que empregava, mas apenas pela falta de veterinário a que pudessem recorrer. E' verdade que por algum tempo muitos moradores o consultavam para curar dor de dente e outras dores, cobreiro e mastite. Mas a sua fama se baseou no tratamento dos animais, setor para o qual os colonos estavam desprovidos de recursos de qualquer natureza. O animal que estivesse com um 
pedaço de mandioca atravessado na garganta, que sofresse de broca, que tivesse bicheiras ou não pudesse urinar, a rez que tivesse dificuldade em dar cria - eis os verdadeiros "pacientes" de Diogo. E isto apenas na medida em que os colonos não tivessem aprendido, êles próprios, as manipulaçôes correspondentes.

Com referência ao folclore mágico da região de São Bonifácio, Francisco S. G. Schaden escreveu o seguinte: "Não sabemos em que medida o uso das curas de simpatia e dos benzimentos aqui registados se observaram na cultura campesina que os avós dos colonos trouxeram da pátria de origem. E' possivel que a adoção dessas práticas seja mais ou menos rerente, e devida pripcipalmente aos contactos esporádicos que os imigrantes e seus filhos tiveram com a população de ascendência lusa" 9. A inIlluência aculturativa é manifestada, por exemplo, na transmissão de padrões de magia por individuos luso-brasileiros e nas benzeduras acompanhadas de rezas em português. Estas são, porém, menos comuns do que aquelas em que se usam textos em língua alemã. Alguns dêstes textos alemães são de natureza essencialmente mágica. Assim, a "reza" para liqüidar as pragas na roça de milho: "Es zogen drei Jungfrauen durch das Land, die trugen drei Rosen in der Hand; die eine war weiss, die zweite war rot, die dritte war schwarz, die macht alles tot". Em outros se combina a fórmula mágica com a oração cristã aprendida na família ou na igreja. Para fazer baixar a febre, por exemplo, toma-se uma canequinha e tira-se um pouco dágua dum riacho, dizendo: "Ich gehe an diesen Fluss und schöpfe Jesu Christi Blut; das soll sein für 99 Leibfieber". Em seguida, despejando a água, reza-se ou um Padre Nosso ou um Creio em Deus Padre 10 .

Vê-se bem, neste e em grande número de outros padrões registrados em São Bonifácio, o corriqueiro "conflito intracultural" entre magia e religião, que, entretanto, năo se apresenta como incompatibilidade. De um lado, o padrão mágico; do outro, o espírito de obediência ou ortodoxia religiosa, que reprova os recursos mágicos e manda rezar a Deus para que socorra o enfêrmo. Por fim o conflito se acomoda pela formação de um sincretismo mágico-religioso, em que o elemento religioso predomina sôbre o mágico, despojando-o de uma de suas características essenciais, i. é, do seu significado.

Nota-se, embora a titulo de exceção, que em uma ou outra comunidade as práticas mágicas sofreram notável incremento em solo brasileiro, não em conseqüência de algum processo aculturativo, mas em virtude do isolamento e do abandono em que ficaram certas colônias. Nestes casos cabem à magia funções que em outras circunstâncias se ligam à vida religiosa e à assistência médica. E' eloqüente, a êste respeito, o testemunho do pastor duma comunidade protestante da colônia de São Lourenço, no Rio Grande do Sul, que durante vários anos exerceu o ministério numa paró- 
quia de pomeranos que por longo tempo ficara entregue a si mesma: "Também as superstições se haviam desenvolvido assustadoramente nos referidos primeiros 25 anos. E' verdade que a população já as tinha trazido da Alemanha; mas foi no Brasil que passaram a vicejar de fato. Por muito tempo, as práticas de esconjuro, os exorcismos por sôpro e as curas de simpatia estiveram na ordem do dia. Ainda hoje se acredita muitas vêzes não ser possível dispensar essas artes negras. Mais ainda, eram até consideradas como forma especial de piedade. Os velhos colonos vindos da Alemanha possuíam, ainda, quase todos, bom cabedal de conhecimentos religiosos, dispondo, além disso, de certa medida de bons costumes e espírito relativamente esclarecido; mas a geração de alemães que surgiu mais tarde e que cresceu no Brasil, destituída de senso crítico, fàcilmente se deixava levar a umas tantas maquinações escusas"11. A situação especial da colônia formava, pois, ambiente propício para que na cultura a magia viesse a ocupar lugar mais importante do que na terra de origem, sem que isto necessàriamente decorresse do contacto com representantes de outra população, portadores de padrões estranhos. A julgar pelos testemunhos existentes, porém, a disposição para o incremento da magia no interior da própria cultura dos colonos não parece ter sido regra geral, mas fenômeno excepcional em alguns núcleos inteiramente abandonados a si próprios no tocante à medicina e à religião. E não estamos em condições de decidir à luz do material disponível qual das duas confissões cristãs, a católica ou a protestante, leva a palma neste particular.

Sabemos que em tôdas as comunidades humanas há uma "filosofia popular", difusa, ligada às concepções religiosas, aos valores morais e às vivências estéticas. Se fôsse verdade, como às vêzes se pensa, que ela sempre se concretiza em mitos, contos e lendas, trovas e adivinhas, deverse-ia admitir a quase-inexistência de tal "filosofia" em muitas comunidades teuto-brasileiras. Em certo serłido é mesmo possível concordar com tal ponto de vista, porque a influência oficial do Cristianismo, mormente em colônias católicas, se revela de tal modo absorvente e determinante na formação da mentalidade rural teuto-brasileira, que não é fácil o desenvolvimento de formas epifíticas, às vêzes em oposição à doutrina ortodoxa e ao comportamento religioso aprovado. Isto significa que o "saber poFular", embora se trate de meio essencialmente rural, é controlado, mesmo em suas manifestações corriqueiras, pelo saber institucionalizado de natureza erudita transmitido pela Igreja. Tal é a situação em numerosas ou mesmo em quase tôdas as comunidades teuto-brasileiras católicas, mas igualmente em muitas de credo protestante. "Superstições" e práticas mágicas, por exemplo, tendem a ser condenadas como crenças heterodoxas e reprováveis ou como recursos clandestinos, sendo combatidas sistemàticamente pelo sacerdote, em certo sentido a maior autoridade da colonia. E' enérgica, às vêzes. a reação contra as benzeduras, que, pelo menos em 
parte, se aplicam em situações para as quais o sacerdote dispõe de benzimentos de acôrdo com o ritual da Igreja. E como não raro se recomenda aos fiéis a reza como substitutivo da técnica mágica, é fácil compreender a fusão de magia e catolicismo oficial em certas comunidades teutobrasileiras.

Sôbre êsse fenômeno possuimos algum naterial recolhido em São Bonifácio por Francisco S. G. Schaden. A pesquisa, realizada há já mais de um decênio, revelou que ali o principal fator contrário ao desenvolvimento cas práticas mágicas é a reprovação eclesiástica, se bem que a crença em sua eficácia se apresente bastante generalizada na comunidade, embora com notáveis variações de grau. De outro lado, uma das causas mais importantes de sua existência é, mais uma vez, o isolamento em que a colônia viveu durante decênios: pela dificuldade de se obterem recursos médicos, recorria-se a "poderes extraordinários". Com o tempo, as manipulas.ões contra dores de cabeça ou de dentes cederam lugar ao emprêgo dá cafiaspirina e do melhoral.

Em todo caso, a grande maioria das benzeduras e curas de simpatia tradicionais, na medida em que subsistem, é intimamente ligada à religião oficial. As próprias analogias que ocorrem nas fórmulas verbais são quase sempre tiradas da esfera religiosa e por vêzes de maneira bem forçada. Assim, por exemplo, quando numa benzedura para curar estados de angústia ou ânsia se usam as palavras "Weich aus der Rippe, so wie Jesus cuus der Krippe". (Sai da costela, como Jesus do presépio) 12. - E', aliás, - que de há muito se tem observado na magia rural de todos os países cristãos.

Em que sentido se faz notar a influência aculturativa no domínio da magia? Além da transmissão de determinadas crenças, fórmulas ou manipulações, verifica-se haver transformação fundamental no tocante aos agentes ou sujeitos. Não raro, as culturas campesinas alemãs repudiam decididamente o especialista em assuntos mágicos, como reminiscência talvez de velhos tempos em que se queimavam bruxas e feiticeiras. Por seu turno, o caboclo costuma aceitar e atribuir mesmo status privilegiado ao curandeiro ou ao rezador, que em muitas regiões consegue fàcilmente arvorar-se em conselheiro ou chefe espiritual da população. Tal não é fácil ocorrer nas colônias teuto-brasileiras. O famoso caso dos Mucker constiŁui significativa exceção. Parece que o fenômeno aculturativo de maior alcance neste setor é a aceitação de "especialista", não como líder carismático, mas apenas em sua qualidade de manipulador mágico. Em São Bonifácio, por exemplo, sempre se fêz distinção entre indivíduos ineptos e outros bem dotados para determinadas práticas mágicas, mas, com exreção de uns poucos casos especiais (por exemplo, ter nascido em SextaFeira Santa para poder curar o panarício), basta a simples iniciação do individuo e alguma experiência, contanto que se tome o cuidado de esco- 
ther para iniciador pessoa de sexo diferente do do iniciando. Há alguns decênios a situação mudou. Um curandeiro caboclo, o já mencionado Diogo Pereira. estabelecendo-se na colônia, logo criou fama como benzedor. De-pois dêles, outros "especialistas" luso-brasileiros, em parte curandeiros espíritas, tiveram aceitação entre a população teuta da localidade, quer protestante, quer católica. E alguns teuto-brasileiros que, por sua vez, vieram atuar como benzedores haviam aprendido a arte fora da colonia, em ambiente luso-brasileiro.

Conquanto tal transformação se tenha operado - aceitação do curandeiro como "especialista" com status relativamente favorável -, subsiste uma diferença entre a atitude do caboclo e a do colono. Aquêle tende a ligar a eficácia dos ritos a faculdades especiais do curandeiro, a considerála decorrente de poderes pessoais (o que não exclui, é claro, a existência de ritos ao alcance de qualquer indivíduo), enquanto o teuto a liga mais às práticas mágicas em si. Basta, portanto, aprendê-las para poder aplicá-las e, assim, evitar as despesas com o curandeiro. Desnecessário pôr em evidência que tal atitude equivale a canal de infiltração de novos elementos culturais.

$\mathrm{Na}$ cultura teuto-brasileira, na medida em que o têrmo cabe, o desaparecimento mais ou menos rápido da magia está condicionado à ação de vários fatôres: à influência do padre católico e do pastor protestante, que a reprovam; à existência de recursos médicos e veterinários racionais e, finalmente, ao avanço paulatino dos padrões da civilização urbana, que vão penetrando nos recantos mais afastados das zonas coloniais. À medida uue se fortalecem êsses elementos, destrói-se a atmosfera cultural necessária à sobrevivência das práticas mágicas no seio da população.

Quanto ao aspecto pròpriamente aculturativo no setor da magia, nota-se que o fato de serem os padrões estranhos apresentados, em sua quase totalidade, pelo elemento caboclo, isto é, por aquêles representantes da população luso-brasileira que não gozam de muito prestígio entre os colonos, se revela em geral obstáculo à sua aceitação. Esta parece tornar-se mais fácil quando os portadores são indivíduos provenientes do meio urbano. Algumas das famílias mais ou menos remediadas de São Bonifácio consultam médicos ou curandeiros "espíritas" de cidades luso-brasileiras. embora êstes trabalhem às vêzes com técnicas exclusivamente mágicas. Mas não deixam de ser casos excepcionais. Até mesmo em zonas de intensa aculturação no Estado de Santa Catarina, como por exemplo na cidade de Joinvile, as crenças mágicas e as práticas de curandeirismo não cncontram terreno fértil. E' o que em 1950 revelou um inquérito realizaco naquela cidade pelo Departamento Estadual de Estatística de Santa Catarina: "Quanto ao curandeirismo, que aqui se registra sem muita freqüência, decorre de dificuldades econômicas ou de situações desespera- 
doras, não sendo propensa a população, de modo geral, a se valer dêsses recursos" 13 .

Iriamos muito longe se quiséssemos explorar devidamente os aspectos aqui assinalados. Mas não foi esta a nossa intenção. Julgamos de interêsse, apenas, chamar a atenção para algumas perspectivas aproveitáveis pelos que se queiram dedicar a um levantamento cientifico do folclore teuto-brasileiro, tão mal conhecido por enquanto. E esperamos que as idéias e os fatos aqui expostos sirvam de estimulo para que um número suficiente de pesquisadores leve avante a coleta e a interpretação do folclore das regiões coloniais. De caso pensado restringimos o nosso trabaIho pràticamente a elementos observados em uma área restrita, a que tem por centro a localidade de São Bonifácio, no sul do Estado de Santa Catarina. Mais ainda, limitamos a discussão a algumas crenças populares e a uns poucos fatos relacionados com a magia, deixando de lado o vasto campo das práticas, concepções e crenças relativas ao ciclo de vida, das atividades festivas e recreativas, das particularidades da técnica tradicional e de outros domínios da cultura material. Tudo isto deveria ser analisado em sua vinculação mais ou menos estreita com o mundo físico e humano que cerca o colono e com vistas aos fatôres de persistência, de transformação e de criação original. E sabemos todos que em preocupações científicas dessa ordem não convém ignorar a questão fundamental de se descobrir em que sentido é legitima a generalização de afirmações válidas para tal ou qual comunidade. Mas para abordá-la com expectativa de êxito, hão de ser empreendidas primeiro algumas dezenas de cuidadosas investigações locais, em áreas escolhidas do ponto de vista da situação ecológiça, cultural e histórica. Cumpre que a fase dos trabalhos comparativos seja precedida por outra, de pequenos estudos monográficos, executados com o necessário rigor de método e segundo um plano de coordenação elaborado com vistas aos problemas da moderna Antropologia Cultural. E acreditamos que o atual desenvolvimento das ciências humanas nø Brasil já nos autoriza a considerar viável uma emprêsa dessa envergadura.

\section{NOTAS}

1) Artur Ramos, Introdução à Antropologia Brasileira, vol. 2.०, pág. 554. Rio de Janeiro, 1947.

2) Ibidem.

3) Carlos Henrique Oberacker Jr., "Transformações da língua alemã no Brasil", Revista de Antropologia, vol. 5. ${ }^{\circ}$, págs. 1-36. São Paulo, 1957.

4) Raúl Deeke, "Folclore em Blumenau...?" Em: Centenário de Blumenau, págs. 369-372. Blumenau, 1950.

5) Ibidem. 
6) Cf. Francisco S. G. Schaden, Volksglaube und Volksbräuche in São Bonifácio, manuscrito, págs. 30-34.

7) Ralph Linton, prefácio à obra The Individual and his Society, de Abram Kardiner, pág. X. Nova York, 1939.

8) Algumas observações de Francisco S. G. Schaden sôbre a figura do benzedor luso-brasileiro Diogo Pereira foram publicadas por Emílio Willems em seu livro A Aculturação dos Alemães no Brasil, págs. 396-399. São Paulo, 1946.

9) Francisco S. G. Schaden, "Magia e crenças populares numa comunidade teuto-brasileira", Sociologia, vol. 8. ${ }^{\circ}$, págs. 77-87. São Paulo, 1946. Pág. 78.

10) Elementos colhidos por Francisco S. G. Schaden, a quem devemos também os demais dados sôbre São Bonifácio aqui discutidos.

11) Karl Heinrich Oberacker, Im Sonnenland Brasilien, pág. 140. Karlsruhe, 1932 .

12) Francisco S. G. Schaden, "Magia e crenças populares numa comunidade teuto-brasileira", cit., pág. 80 .

13) Boletim Trimestral da Sub-Comissão Catarinense de Folclore, ano $1 .^{\circ}$, n. ${ }^{\circ}$, págs. 40-41. Florianópolis, junho de 1950. 



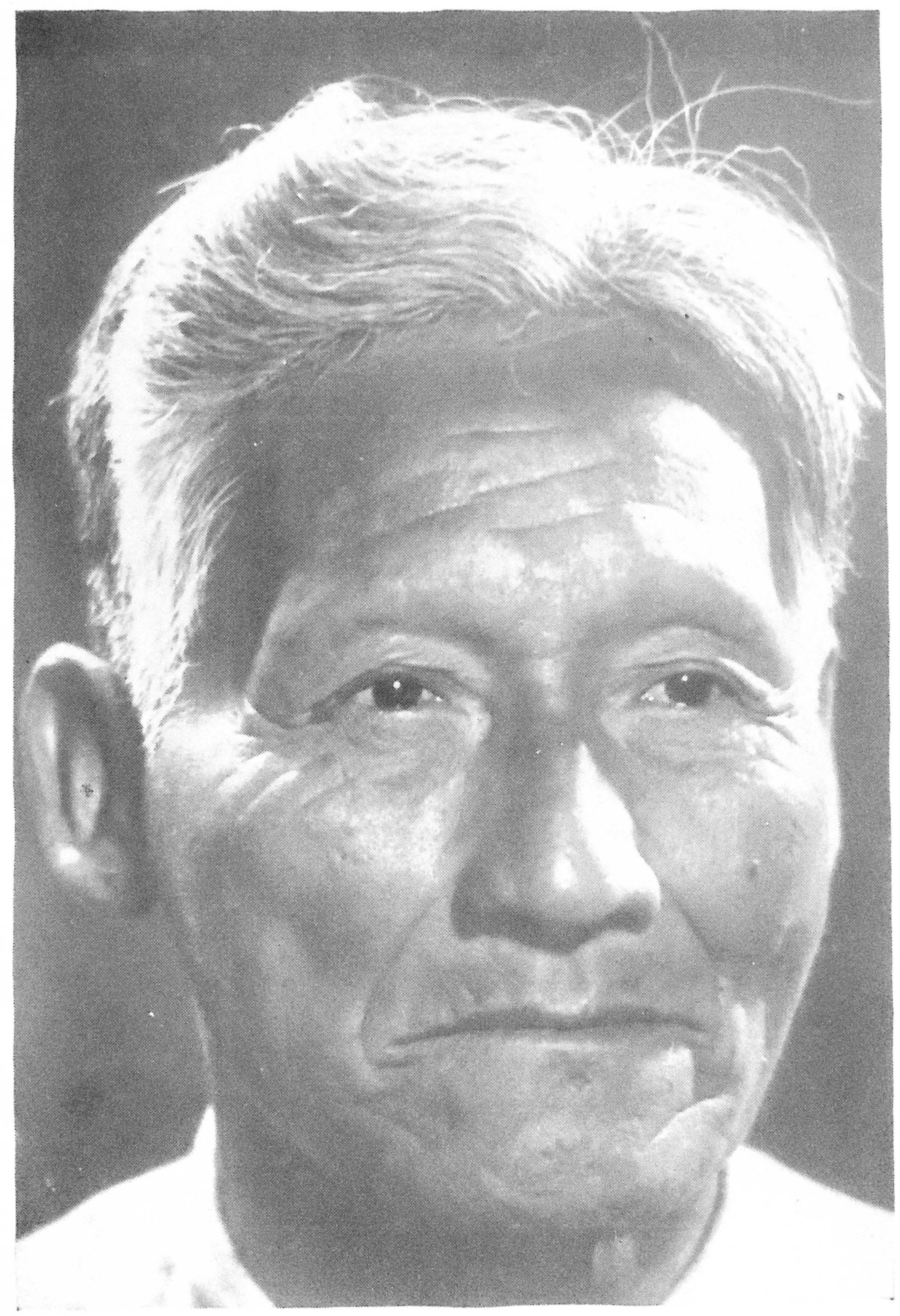

Fotografia de Tiago Aipobureu, tirada pouco antes de sua morte. Nota-se claramente, sob o lábio inferior, o orificio destinado a receber o "boe ennogoddát" (adômo labial para bomens). 